\title{
EL KADID A TRADITIONAL SALTED DRIED CAMEL MEAT FROM ALGERIA: CONTRIBUTION TO THE STUDY OF THE COMPOSITION IN BIOGENIC AMINE, ORGANIC ACID, AROMATIC PROFILE AND MICROBIAL BIODIVERSITY
}

\author{
Amina Bouchefra ${ }^{1,2}$, Tayeb Idoui ${ }^{1,2}$, Chiara Montanari ${ }^{3}$ \\ ${ }^{1}$ Laboratory of Biotechnology, Environment and Health, University Mohamed Seddik Benyahia of Jijel,Ouled \\ Aissa City, 18000 Algeria. \\ ${ }^{2}$ Department of Applied Microbiology and Food Sciences, University Mohamed Seddik Benyahia of Jijel,Ouled \\ Aissa City, 18000 Algeria. \\ ${ }^{3}$ Centro Interdipartimentale di Ricerca Industriale Agroalimentare Universitàdegli Studi di Bologna Via Quinto \\ Bucci 33647521 Cesena (FC), Italy. \\ هaminabouchefral@yahoo.fr \\ https://doi.org/10.34302/crpjfst/2020.12.4.9

\begin{tabular}{|c|c|}
\hline Article history: & 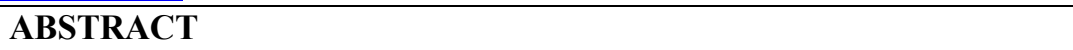 \\
\hline $\begin{array}{l}\text { Received: } \\
\quad 3 \text { January } 2020\end{array}$ & \multirow{8}{*}{$\begin{array}{l}\text { Many meat preparations are manufactured in North Africa.in Algeria, the } \\
\text { dried salted camel meat is called El kadid. The first analysis of the } \\
\text { composition of biogenic amine, organic acid and aromatic profile of this } \\
\text { traditional meat was carried out in this study. El kadid is obtained by salting, } \\
\text { maceration and drying of camel meat. The results showed that the product } \\
\text { contains lactic acid }(6.22 \mathrm{~g} / \mathrm{kg}) \text {, acetic acid }(<1 \mathrm{~g} / \mathrm{kg}) \text {. Biogenic amines } \\
\text { are present at very low concentrations }(<20 \mathrm{mg} / \mathrm{kg}) \text {. The aromatic profile } \\
\text { highlighted the presence of more than } 60 \mathrm{molecules} \mathrm{belonging} \mathrm{to} \mathrm{different} \\
\text { chemical classes, such as aldehydes, ketones and alcohols. El Kadid presente } \\
\text { has a rich microbiological niche (Enterobacteriaceae Latic acid bateria } \\
\text { Coagulase negative microstaphylococci yeast, Enterococci and } E \text { coli). }\end{array}$} \\
\hline Accepted: & \\
\hline 1 August 2020 & \\
\hline $\begin{array}{l}\text { Keywords: } \\
\text { El kadid; }\end{array}$ & \\
\hline Biogenic amine; & \\
\hline Aromatic profile; & \\
\hline id; & \\
\hline & \\
\hline
\end{tabular}

\section{Introduction}

The breeding of large camelids remains marginal on a global scale: $0.4 \%$ of the world's herbivorepopulation, $1.4 \%$ of the domestic herbivore biomass (HDB) (Faye, 2009). According to the FAO, camelmeat production in Algeria will increase from 4800 Tons in 2010 to 5948 Tons in 2017. The importance of camels as meat-producing animals is gradually increasing due to the high nutritional value of their meat, in addition to their ability to survive in difficult environmental conditions. The composition of camel meat is similar to that of meat from other species where the inverse relationship exists between humidity and protein and fat content. In addition to its importance in determining the nutritional value of the meat, it is also an important indicator of the functionality of the meat (Bekhit and Farouk, 2013). Meat in particular is a very favourable breeding ground for most microbial contaminations. It is a difficult food to preserve. The shelf life of this product depends on the degree of acidity and water content of the product as well as certain external parameters such as air, microorganisms, temperature and light (Berkel et al., 2004; Pal et al., 2018). There are many methods of meat preservation based on different principles: conventional methods and potential methods (Prokopov and Tanchev, 2004). Due to the high ambient temperatures and lack of refrigeration capacity most areas where camel meat is produced involve the use of artisanal curing technology (Kadim et al., 2013). Large 
amounts of meat products are customarily prepared for the Eid-ul-Adha festival in Algeria; the excess has to be preserved for later consumption (Bouchefra et al., 2019). El kadid, a typical product of the Maghreb region (Morocco, Algeria and Tunisia), is obtained using this basic technology to produce stable salted cured meat that can be stored at room temperature for more than a year (Touzi and Merzaia-Blama,2008; Benkerroum, 2013). Unfortunately, there is no data on the composition and microbial biodiversity of dried salted camel meat, El Kadid, produced in Algeria. In this context, this study focuses on the traditional process of preparation of camelin cured salted dried meat (El Kadid) and an analysis of the composition of biogenic amines, organic acid and aromatic profile of El kadid.

\section{Materials and methods}

\subsection{Traditional process for the preparation of salted dried meat (EI Kadid)}

The sample analyzed is a typical product of the Algerian terroir based on dried salted camel meat known as El Kadid. The camel meat is washed under running water and then cut into strips (approximately $1 \mathrm{~cm}$ wide and 10-20 cm long). Then other ingredients such as coarse salt, pepper and olive oil are added to the strips of meat. The meat is left to macerate overnight at $4^{\circ} \mathrm{C}$. In the morning, we proceeded to the drying phase, during which the strips of meat are dried on ropes under the sun for about 7 days. During the drying period, the meat is turned periodically, in order to obtain an even drying of the final product. The drying phase ends when the meat reaches a brown colour and a good fibrous appearance. Finally, the strips of meat are cut into 2 to $3 \mathrm{~cm}$ long pieces and placed inside a sterile jar, sealed and kept at room temperature (Bouchefra et al., 2019).

\subsection{Analysis of biogenic amine content}

The qualitative-quantitative analysis of the biogenic amines was carried out by the technique of high-pressure liquid chromatography (HPLC). The first extraction phase was carried out as follows: $10 \mathrm{~g}$ of the El kadid sample were weighed, to which $20 \mathrm{ml}$ of an aqueous solution of trichloroacetic acid (TCA 5\%) (Sigma-Aldrich, St Louis, MO, U.S.A.) was added. The samples are then left for 30 minutes in a thermostatically controlled bath without stirring at $75^{\circ} \mathrm{C}$. The extract is then centrifuged (Rotor JA 25: 50, $2700 \mathrm{rpm}, 10$ minutes, $4{ }^{\circ} \mathrm{C}$ ) and filtered on filter paper into a $50 \mathrm{ml}$ bottle. The extracts were derived according to the method described by (Martuscelli et al., 2001) and then injected into (a Jasco PU-2089 Plus HPLC system with a Rheodyne manual injector with $20 \mu \mathrm{l}$ loops and a Jasco UV-VIS UV 2070 Plus UV detector at $254 \mathrm{~nm}$ ). For the analysis, we used a $\mathrm{C} 18$ reverse phase chromatographic column (Waters Spherisorb ODS2, 150x4.6 $\mathrm{mm}, 3 \mathrm{uM}$ ) with the pre-column (Waters Spherisorb S5 ODS2, 4.6x10mm). The quantification of the amines occurs by using external calibration curves, obtained with amines from standard solutions (histamine, 2phenylethylamine, tyramine, putrescine, cadaverine, spermine and spermidine) at different concentrations $(10,20,30,50,75$ and $100 \mathrm{ppm}$ ) which are subjected to the same derivatization procedure.

\subsection{Analysis of organic acid content}

The determination of the organic acids was carried out by HPLC injection of the El kadid sample, following an extraction treatment. $20 \mathrm{ml}$ of $0.01 \mathrm{~N} \mathrm{H} 2 \mathrm{SO} 4$ solution was added to $10 \mathrm{~g}$ of the sample. The solution was left under stirring at $30^{\circ} \mathrm{C}$ for 30 minutes. The supernatant was filtered through Whatman No. 1 paper filters into $10 \mathrm{ml}$ bottles and brought to volume $(50 \mathrm{ml})$ with the same extraction acid. The resulting sample was injected into a (Jasco PU-2089 Plus HPLC system with a manual injector model Rheodyne with a loop from $20 \mu \mathrm{l}$ ). For the analysis we used an Aminex Bio-Rad chromatographic column (Bio-130 Rad Laboratories, Hertfordshire, UK) HPX-H $(300 \times 7.8 \mathrm{~mm})$, maintained in an oven at $65^{\circ} \mathrm{C}$. The mobile phase is characterized by the $0.005 \mathrm{M} \mathrm{H} 2 \mathrm{SO} 4$ eluent at a flow rate of 0.600 $\mathrm{ml} / \mathrm{min}$. The detector used is of UV type and the analysis is performed at $210 \mathrm{~nm}$. The 
chromatographic peaks were compared with the chromatogram obtained by injection of standard solutions of organic acids of interest and thus identified by comparison with the retention time of standard solutions of different organic acids thanks to retention times. The quantification of the organic acids is done by using external calibration curves, obtained with standard acid solutions (lactic acid and acetic acid) at different concentrations (Montanari et al., 2014).

\subsection{Analysis of the aromatic profile}

The aromatic profile of El Kadid was determined by the technique of gas chromatography-mass spectrometry coupled with solid phase microextraction (SPME-GCMS) according to the method of (Tabanelli et al.,2015) :Three g of El Kadid were placed in a sterilized vial, sealed by PTFE / silicone partitions and heated at $47^{\circ} \mathrm{C}$ for $50 \mathrm{~min}$. Volatile compounds were adsorbed for $40 \mathrm{~min}$ on a fused silica fiber covered with $75 \mathrm{~mm}$ Carboxen Polydimethyl Siloxane (CAR / PDMS Stable Flex) (Supelco, Steinheim, Germany). The adsorbed molecules were desorbed in the gas chromatograph for $10 \mathrm{~min}$. For peak detection, an Agilent Hewlette Packard 6890 GC gas chromatograph equipped with a 5970 MSD MS detector (HewlettePackard, Geneva, Switzerland) and a Varian Chrompack CP Wax $52 \mathrm{CB}$ capillary column $(50 \mathrm{~m} \times 320 \mu \mathrm{m} \sim 1.2$ $\mu \mathrm{m})$, fused silica capillary column (Chrompack, Middelburg, the Netherlands) as the stationary phase were used. The injection conditions were: injection temperature, $250{ }^{\circ} \mathrm{C}$; detector temperature, $220{ }^{\circ} \mathrm{C}$; carrier gas flow rate $(\mathrm{He})$, $1 \mathrm{ml} / \mathrm{min}$. The furnace temperature was programmed as follows: $50^{\circ} \mathrm{C}$ for $1 \mathrm{~min}$; from $50^{\circ} \mathrm{C}$ to $65^{\circ} \mathrm{C}$, at $4.5^{\circ} \mathrm{C} / \mathrm{min}$; from $65^{\circ} \mathrm{C}$ to $230^{\circ} \mathrm{C}$, at $10^{\circ} \mathrm{C} / \mathrm{min}$, then holding for 25 min.Identification of volatile peaks was performed by computer matching of mass spectral data with those of compounds contained in the Agilent Hewlette Packard NIST 98 and Wiley Version 6 mass spectral database.

\subsection{Mirobial biodiversity analysis}

In order to assess the biodiversity of the microflora present in El-kadid salt-dried meat, sampling was carried out on the surface, using different selective culture media according to the method described by (Tabanelli et al., 2012):

-MRS agar (De Man, Rogosa, Sharpe): used for the enumeration of lactic acid bacteria by the surface inoculation method. After inoculation, the plates were incubated at $30^{\circ}$ for 48 hours. The medium is prepared with a formulation (Oxoid, Basingstoke, UK).

-Glose Baird Parker: used for the growth of Gram-positive bacteria (Microcaccaceae and Staphylococcaceae). The medium is prepared with a formulation (Oxoid, Basingstoke, UK), after sterilization an emulsion of egg yolk and tellurite is added (Oxoid, Basingstoke, UK), to promote colony growth. After inoculation, the boxes were incubated at $30^{\circ}$ for 48 hours.

-Slanetz and Bartley medium: suitable for the enumeration of enterococci by surface seeding. The medium was obtained using a formulation (Oxoid, Basingstoke, UK). The boxes were incubated at $42^{\circ} \mathrm{C}$ for 48 hours.

-VRBGA medium (glucose red bile agar, oxoid): for the enumeration of Enterobacteriaceae. The medium is prepared using a formulation (Oxid, Basingstoke, UK). The boxes were incubated at $37^{\circ} \mathrm{C}$ for 24 hours. - PCA medium (Plate Count Agar,Oxoid): for the 174 enumeration of the total aerobic mesophyllic flora by surface seeding. The medium was obtained by the use of a formulation (Oxoid, Basingstoke, UK). The boxes were incubated at $30^{\circ} \mathrm{C}$ for 48 hours.

- SAB medium (Sabouraud Dextrose Agar, Oxoid): for the enumeration of yeasts by surface seeding. The medium was obtained using a formulation (Oxoid, Basingstoke, UK). The medium is supplemented with $200 \mathrm{mg} / \mathrm{L}$ of chloramphenicol to inhibit bacterial growth. After inoculation, the boxes were incubated at $28^{\circ} \mathrm{C}$ for 72 hours.

-VRBLA medium (Violet Red Bile Agar, Oxoid), supplemented with (4methylumbelifery-B-D glucuronide, Oxoid) is 
used for the determination of Escherichia coli. The medium has been prepared using a formulation (Oxoid, Basingstoke, UK). Once inoculated, the boxes were incubated at $37^{\circ} \mathrm{C}$ for 24 hours and then observed with UV light at 366 $\mathrm{nm}$ to count the fluorescent colonies.

\subsection{Data analysis}

The results are presented as the mean value \pm standard deviation (SD) of three experiments Microsoft Excel 2016 was used for the data analysis.

\section{Results and discussions}

The composition in biogenic amine, organic acid, aromatic profile and microbial biodiversity of El Kadid has not been documented before. The results of biogenic amine and organic acid are reported in Table 1. Among the organic acids, lactic acid is present in large quantities $(6.22 \mathrm{~g} / \mathrm{kg})$, while acetic acid is present in small quantities $(<1 \mathrm{~g} / \mathrm{kg})$. The analysis of biogenic amines which are substances derived from microbial metabolism (especially enterobacteria and lactic acid bacteria) that may pose a risk to the health of the consumer, has shown that these molecules are present at very low concentrations $(<20 \mathrm{mg} / \mathrm{kg})$. Histamine, putrescine and cadaverine are likely to result from the activity of Enterobacteriaceae (also present in the finished product) but their concentration is nevertheless below the amounts that could cause damage to the human organism. The same can be said of tyramine, the main producers of which are 196 lactic acid bacteria and in particular enterococci.

Table 1. Values of Organic Components and Biogenic Amines of El Kadid.

\begin{tabular}{|c|c|}
\hline Acide lactique (g/Kg) & $6.22( \pm 0.76)$ \\
\hline Acide acétique (g/Kg) & $0.58( \pm 0.06)$ \\
\hline Histamine (mg/Kg) & $12.31( \pm 3.44)$ \\
\hline Tiramine(mg/Kg) & $18.61( \pm 5.33)$ \\
\hline Putriscine(mg/Kg) & $9.10( \pm 1.43)$ \\
\hline Cadavérine(mg/Kg) & $15.22( \pm 2.79)$ \\
\hline
\end{tabular}

Results are expressed as means \pm standard deviation of three measurements.

Table 2. Microbiological counts $\mathrm{Log}(\mathrm{CFU} / \mathrm{g})$ of El Kadid product.

\begin{tabular}{|l|l|}
\hline Enterobacteriaceae & $2,50( \pm 0,17)$ \\
\hline Escherichia coli & $<1$ \\
\hline Latic acid bateria & $2,93( \pm 0,10)$ \\
\hline Coagulase-negative microstaphylococci & $6,16( \pm 0,24)$ \\
\hline Enterococci & $2,08( \pm 0,11)$ \\
\hline Yeast & $1,67( \pm 0,20)$ \\
\hline Total mesophyllic flora & $6,24( \pm 0,37)$ \\
\hline
\end{tabular}

Results are expressed as means \pm standard deviation of three measurements.

The aromatic profile highlighted the presence of more than 60 molecules (Figure 1) belonging to different chemical classes, such as aldehydes (e.g., hexanal, octanal, nonanal), ketones (acetoin, 2,3-octanedione) and alcohols (1-octanol, 1-octene-3-ol). Aldehydes were the dominant class, probably due to sun drying (high temperature, light) which promotes the oxidation of lipids (Figure 2). The organoleptic characteristics of fermented meat derive from the combination of lipolytic and proteolytic, oxidative and endogenous, bacterial or even fungal enzymatic activities. Micro and staphylococci are responsible for the production 
of most of the fermented meat flavour compounds, through the metabolism of amino acids and the consequent decarboxylation of aldehydes. Amino acids, especially leucine, isoleucine and valine, are transformed into alcohols and aldehydes, compounds related to the final flavour of the product. Moulds and yeasts can also contribute to the characterisation of the flavour profile of meat, thanks to their proteolytic and lipolytic capacities. Lactate oxidation, amino acid conversion and lipid oxidation by these microorganisms can contribute to the sensory quality of the finished product (Ravyts et al., 2012).

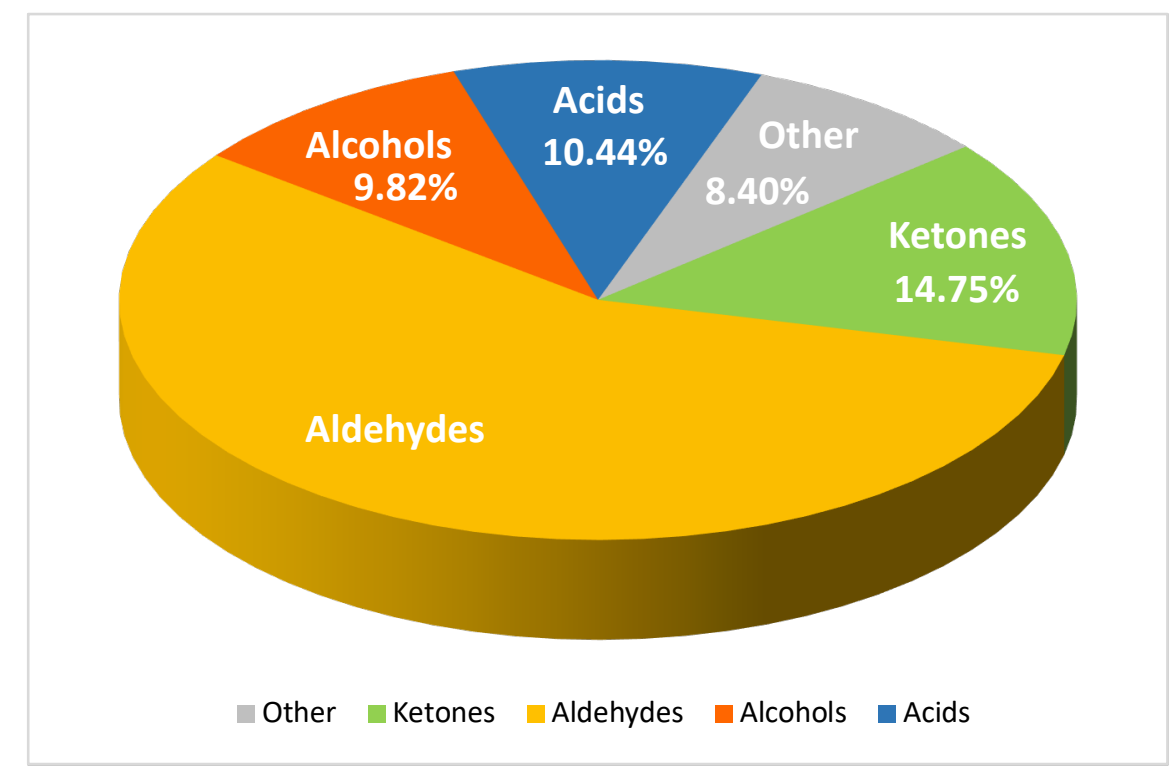

Figure 1. Volatile compounds grouped according to chemical classes (\%) in El Kadid. Results are the mean of three samples. In bracket the standard deviation is reported.

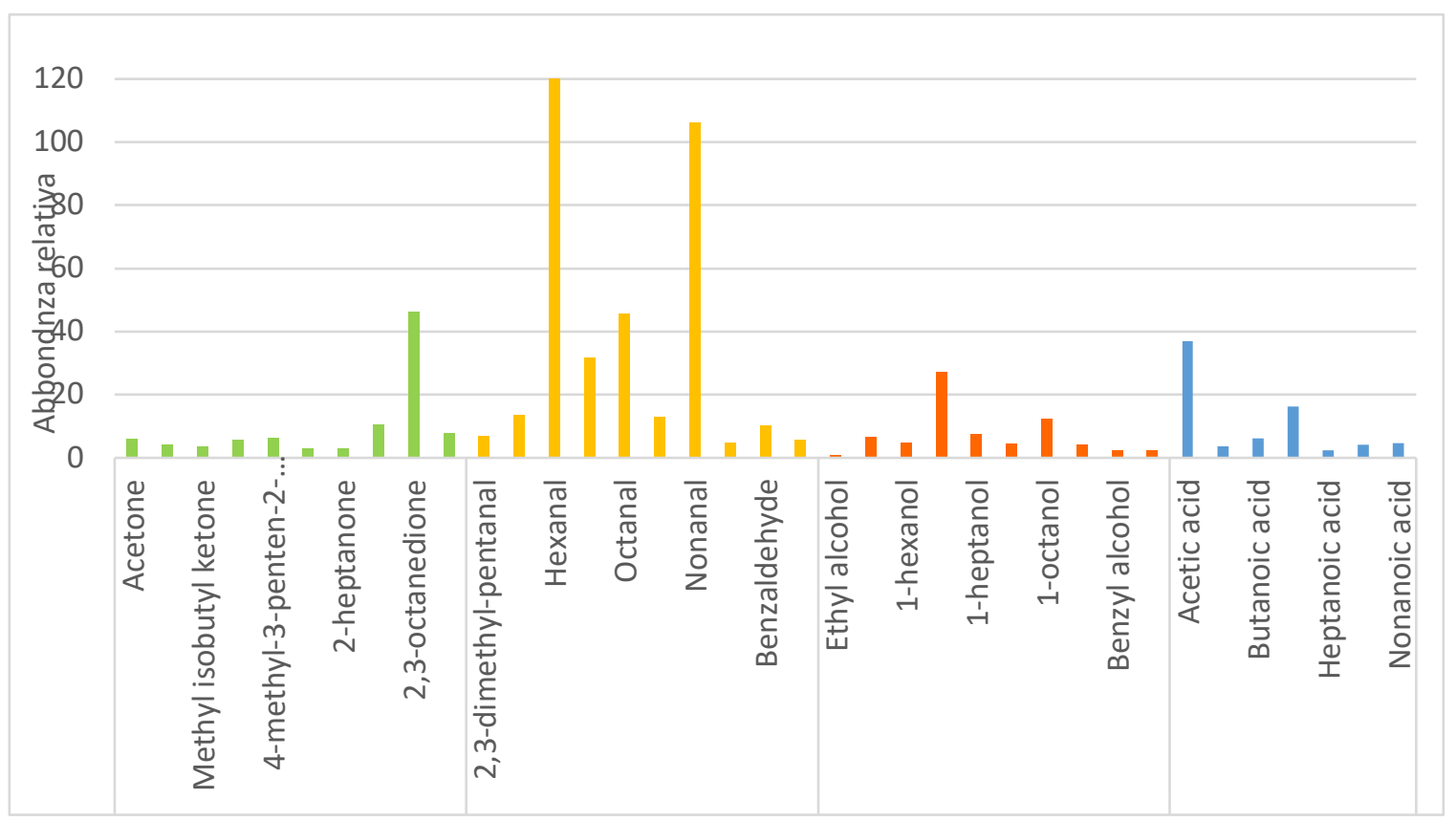

Figure 2. Aldehydes in El Kadid. Results are the mean of three samples. 
The results of the microbiological counts, reported in Table 2, show that the dominant population is represented by coagulase negative microstaphylococci (CNC) (6.16 Log CFU/g) and yeasts, present at a concentration of 4.67 Log CFU/g. Other microbial groups are present at lower levels (2-3 Log CFU/g), in particular lactic bacteria, enterococci and enterobacteria. The latter probably derive from the handling of the product, which during the process is daily exposed to the sun during the day and then collected to be placed inside for the night. The value of the total mesophilic charge is almost superimposable with $\mathrm{CNC}$ counts. The microflora found is in line with what reported in the literature, where several authors have 218 highlighted staphylococci as the dominant population of this type of products (Bennani et al.,1995; Benanni et al.,2000).

\section{Conclusions}

The analysis of the composition of El kadid, a camel meat (Camelus dromadarius) obtained by drying after salting and marinating in olive oil typical of Algeria has shown that it contains small quantities of biogenic amines which does not constitute a health risk for the consumer. El kadid is characterized by a diversified aromatic profile which makes it appreciable by the tasters.Lactic acide bacteria are certainly the microorganisms of greatest interest from an industrial point of view and in particular for the selection of new starter and/or bioprotective cultures. The study of this product seems interesting to identify the risks associated with production and develop appropriate strategies to industrial level.

\section{References}

Bekhit, A.E., Farouk, M.M. (2013). Nutritive and Health Value of Camel Meat. In: I.T. Kadim (Ed.), Camel meat and meat products. (pp.205-223), London: CAB International.

Benkerroum, N. (2013). Traditional fermented foods of North African countries: technology and food safety challenges with regard to microbiological risks.
Comprehensive Reviews in Food Science and Food Safety, 12, 54-89.

Bennani, L., Faid, M., Bouseta, A. (2000). Experimental manufacturing of kaddid, a salted dried meat product: control of the microorganisms. European Food Research and Technology,211, 153-157.

Bennani, L., Zenati, Y., Faid, M., Ettayebi, M. (1995).Pysico-chemical and microbiological characteristics of a dried salted meat product (Kaddid) in Morocco. Zeitschrift für Lebensmittel-Untersuchung und-Forschung, 201, 528-532.

Berkel, M.V., Boogaard, V.D.B., Heijnen, C. (2004). Salting fish and meat:InThe Preservation of fish and meat, Agrodok Manual (12rd), AgromisaFondation, Wageningen ,(Chapter16).

Bouchefra, A., Idoui, T., Montanari, C. (2019). Phisicochemical characteristics, fatty acid composition and functional properties of the traditional salted dried meat of Camelus Dromedarius from Algerian eastern sahara: El kadid.Carpathian Journal of Food Science and Technology,11(3), 39-49.

Faye, B. (2009).L'élevage des grands camélidés : vers un changement de paradigme. Renc. Rech. Ruminants, 16, 345-348.

Kadim, I.T., Mahgoub, O., Faye, B.,Farouk , M.M .(2013).Camel Meat and Meat Products. London: CAB International, p249. Martuscelli, M., Crudele, M.A., Gardini, F. ,Suzzi, G . (2001). Biogenic amine formation and oxidation by Staphylococcus xylosus strains from artisanal fermented sausages. Letters in Applied Microbiology, 31, 228-232.

Montanari, C., Bargossi, E., Lanciotti, L., Chinnici, F., Gardini, F. ,Tabanelli, G .(2014).Effects of two different sourdoughs on the characteristics of Pandoro, a typical Italian sweet leavened baked good. Food Science and tehnology, 59 (1), 289-299.

Pal, M., Ayele, Y., Patel, A.S., Dulo, F. (2018). Microbiological and hygienic quality of Meat and Meat Products. Beverage and Food World, 45 (5), 21-27. 
Prokopov, T., Tanchev, S. (2004). Methods of foods preservation. In: Food Safety A Practical and Case Study Approach.2006. ISBN-10: 0-387-33509-9.3-24.t, Agrodok Manual (12th Ed.), (pp.25-36), Agromisa Fondation, Wageningen.

Ravyts, F., Vuyst, L.D., Leroy, F. (2012). Bacterial diversity and functionalities in food fermentations. Engineering in Life Sciences, 12, 356-367.

Tabanelli G, Torriani S, Rossi F, Rizzotti L, Gardini F. (2012). Effect of ChemicoPhysical Parameters on the Histidine Decarboxylase (HdcA) Enzymatic Activity in Streptococcus thermophilus PRI60. Journal of Food Science, 77(4).

Tabanelli, G., Bargossi, E., Gardini, A., Lanciotti, R., Magnani, R., Gardini, F., Montanari, C. (2015). Physico-chemical and microbiological characterisation of Italian fermented sausages in relation to their size. Journal of the Science of Food and Agriculture, 96. 2773-2781.

Touzi, A., Merzaia-Blama, A. (2008). La conservation des denrées agroalimentaires par séchage dans les régions sahariennes.Energies Renouvelables SMSTS'08 Alger. p267-272.

\section{Aknowledgment}

This work was supported by a grant of the "Ministère de 1'Enseignement Supérieur et de la Recherche Scientifique" of Algeria (Project PRFU D01N01UN180120200001). 